\title{
TINJAUAN KINERJA POMPA AIR TANPA MOTOR (PATM) DESA ALALE KABUPATEN BONE BOLANGO \\ Disusun Oleh :
}

\author{
Andri Ramadhan Himari \\ Mahasiswa Teknil Sipil \\ STITEK Bina Taruna Gorontalo \\ INDONESIA \\ bukustitek@yahoo.com
}

\begin{abstract}
ABSTRAK
Musim kemarau menjadi masalah utama bagi petani yang hanya mengandalkan suplai air melalui bendungan atau saluran irigasi. Air menjadi barang berharga dan menjadi rebutan. Namun masalah tersebut teratasi dengan adanya Pompa Air Tanpa Motor atau Hidram (Hydraulic Ram). Jenis pompa air ini sangatlah cocok untuk irigasi dan pengadaan air baku. Efisiensinya sangat tinggi karena pompa ini tidak tergantung kepada bahan bakar minyak, listrik ataupun oli mesin, hingga dapat beroperasi 24 jam terus menerus dan juga biaya operasionalnya bisa dikatakan sangat sedikit dan perawatan dan perbaikan sangat mudah, tidak memerlukan tenaga ahli khusus. Tujuan dalam penelitian ini adalah menganalisis ketersediaan air yang dibutuhkan untuk menggerakkan PATM, mengetahui tinjauan kinerja PATM, dan Mengetahui Kondisi PATM. Berdasarkan hasil penelitian debit air yang ada tidak mempengaruhi efisiensi PATM itu sendiri, debit yang diperoleh dalam beberapa tahun terakhir dengan jumlah rerata yang ada adalah 45,332 liter/detik dan untuk kebutuhan debit air pada PATM didapatkan hasil rerata 17,226/detik. PATM adalah teknologi pompa terbaru dengan menggunakan pemanfaatan gravitasi dimana akan menciptakan energi dari hantaman air yang menabrak faksi air lainnya untuk mendorong ke tempat yang lebih tinggi. Kondisi pompa saat ini telah mengalami kerusakan sebanyak 9 unit pompa, hal ini sangat berpengaruh terhadap kebutuhan air baku yang sering dimanfaatkan oleh masyarakat sekitarnya untuk kebutuhan lahan pertanian dan perkebunan.
\end{abstract}

Kata Kunci: Pompa Air Tanpa Motor, Hydraulic Ram, \& Kinerja

\section{PENDAHULUAN}

Bercocok tanam merupakan kegiatan yang tak dapat dipisahkan oleh sebagian masyarakat Indonesia, khususnya masyarakat di Kabupaten Bone Bolango, Provinsi Gorontalo yang masih mengandalkan suplai air dari bendung maupun saluran irigasi setempat untuk kegiatan ini. Sebagian besar mata pencaharian masyarakat di pedesaan utamanya yang bercocok tanam sangat membutuhkan ketersedian pengairan yang mencukupi. Namun masalah kadang muncul ketika musim kemarau tiba, air menjadi barang berharga dan menjadi rebutan walaupun masih ada sungai, sayang letaknya lebih rendah dari lahan pertanian. Namun masalah itu kini bisa diatasi dengan adanya teknologi terbaru, yaitu Pompa Air Tanpa Motor (PATM) atau lebih dikenal lagi dengan sebutan Hidram (Hydraulic Ram). Jenis pompa 
air yang betul - betul tidak memerlukan bahan bakar minyak maupun listrik sehingga bisa menghemat biaya operasional. Jenis pompa air ini sangatlah cocok untuk irigasi dan pengadaan air baku. Efisiensinya sangat tinggi karena pompa ini tidak tergantung kepada bahan bakar minyak, listrik ataupun oli mesin, hingga dapat beroperasi 24 jam terus menerus dan juga biaya operasionalnya bisa dikatakan sangat sedikit dan perawatan dan perbaikan sangat mudah, tidak memerlukan tenaga ahli khusus. Walaupun pada keadaan banjir, pompa tidak akan rusak. Kelebihan pompa air ini umurnya ekonomis, sangat tahan lama, dan bisa dipakai secara teus menerus selama 24 jam tanpa henti.

Provinsi Gorontalo adalah salah satu daerah yang menggunakan Pompa Air Tanpa Motor (PATM), sejak tahun 2005 dibangun PATM sebanyak 15 unit di Kabupaten Gorontalo, setahun kemudian pembangunan kedua di Kabupaten Bone Bolango jumlah PATM sebanyak 40 unit. PATM yang dibangun di Kabupaten Bone Bolango ini memanfaatkan sumber air dari sungai Bone untuk pengairan lahan pertanian dan Danau Perintis.

Pengadaan infrastruktur pompa air tanpa mesin ini diharapkan dapat menanggulangi krisis air terutama pada saat musim kemarau. Pengadaan infrastruktur ini masih belum banyak diperhatikan pemeliharaan dan perawatannya sehingga kinerja dari PATM belum optimal. Oleh karena itu perlu adanya penelitian mengenai Kinerja dari PATM agar dapat menjadi sebuah solusi yang nyata dan dapat menjawab realita saat ini tentang PATM yang merupakan suatu alat untuk menyalurkan air ke daerah dataran tinggi.

\section{RUMUSAN MASALAH}

Berdasarkan identifikasi masalah di atas, yang menjadi rumusan masalah adalah :

1. Bagaimana ketersediaan air yang dibutuhkan untuk menggerakkan PATM.

2. Bagaimana Kinerja dari PATM.

3. Bagaimana Kondisi PATM di Lokasi Penelitian.

\section{TUJUAN PENELITIAN}

Adapun tujuan dari penelitian ini :

1. Untuk mengetahui dan menganalisis ketersediaan air yang dibutuhkan untuk menggerakkan PATM.

2. Untuk mengetahui tinjauan kinerja PATM.

3. Untuk Mengetahui Kondisi PATM.

\section{BATASAN MASALAH}

Batasan maalah dalam penelitian ini adalah :

1. Tinjauan Khusus pada kinerja PATM di Desa Alale Kabupaten Bone Bolango.

2. Kondisi Pompa yang ditinjau pada saat sekarang di tahun 2015.

\section{MANFAAT PENELITIAN}

Manfaat Penelitian ini adalah :

1. Memberikan informasi tentang manfaat dan efisiensi dari pengunaan Pompa Air Tanpa Motor (PATM) untuk masyarakat 
yang notabene mata pencahariaanya sebagian besar bercocok tanam.

2. Merencanakan pembuatan jaringan Pompa Air Tanpa Motor (PATM) dengan efisiensi biaya yang ada.

\section{LANDASAN TEORI}

\section{Pengertian PATM}

Pompa Air Tanpa Motor (PATM) adalah suatu alat untuk memompa dan menaikkan air dari tempat rendah ke tempat yang lebih tinggi dengan cara kerja yang sederhana dan efektif sesuai persyaratan teknisi dan operasionalnya. PATM biasa juga disebut HIDRAM (Hydraulic Ram) pertama kali dikembangkan oleh montgolfier pada tahun 1796 di Italia.

\section{Karakteristik Pompa Hidram}

Karakteristik pompa hidrolik ram atau hidram yang bekerja pada keadaan tertentu dimana jarak antara lubang dan katup limbah konstan, tinggi vertikal tangki pemasukan tetap tinggi, sedangkan tinggi pemompaan berubahubah, ternyata menunjukkan bahwa jumlah denyutan katup limbah tiap menit bertambah pada setiap penambahan tinggi pemompaan. Pompa hidrolik ram yang dirancang dengan baik dapat bekerja baik pada semua keadaan dengan pemeliharaan yang minimum.

Pompa yang terbuat dari bahan besi cor yang kuat dapat bekerja dengan baik hingga bertahun-tahun. Hal ini merupakan penghematan investasi yang luar biasa bagi kelompok petani. Ukuran pompa hidrolik ram ditentukan oleh kapasitas yang dikehendaki dan juga dibatasi oleh jumlah air yang tersedia untuk menggerakkan pompa. Pompa harus dipasang serata mungkin untuk meyakinkan bahwa katup limbah yang diberi beban dapat jatuh tegak lurus ke bawah dengan gesekan sekecil mungkin. Pemasangan pipa juga harus diperhatikan agar tidak ada belokan-belokan tajam atau sudut yang mengurangi kekuatan aliran air.

\section{Komponen PATM}

1. Katup limbah (waste valve).

Katup limbah merupakan salah satu bagian penting dari hidraulik ram, dan harus dirancang dengan baik sehingga berat dan gerakannya dapat disesuaikan. Katup limbah dengan tegangan yang berat dan jarak antara lubang katup dengan karet katup cukup jauh, memungkinkan kecepatan aliran air dalam pipa pemasukan lebih besar, sehingga pada saat katup limbah menutup, terjadi energi tekanan yang besar dan menimbulkan efek palu air (water hammer effect). Katup limbah yang ringan dan gerakannya pendek akan memberikan pukulan atau denyutan yang lebih cepat dan menyebabkan hasil pemompaan lebih besar pada tingggi pemompaan rendah. Penelitian mengenai bentuk dari katup limbah masih kurang, tetapi pada saat ini jenis katup kerdam sederhana kelihatannya bekerja cukup baik. Beberapa model hidraulik ram komersil telah menggunakan jenis katup kerdam yang dilengkapi dengan per tetapi belum diketahui apakah hal tersebut meningkatkan efisiensi ram, yang jelas 
jenis ini menghindari pemakaian "sliding bearing" yang harus diganti bila aus.

2. Katup Pengantar (Delivery Valve)

Katup pengantar harus memepunyai lubang yang besar sehingga memungkinkan air yang dipompa memasuki ruang udara tanpa hambatan pada aliran. Katup ini dapat dibuat dengan bentuk yang sederhana yang dinamakan katup searah (non return). Katup ini dibuat dari karet kaku dan bekerja seperti pada katup kerdam

\section{Ruang Udara (Air Chamber)}

Ruang udara harus dibuat sebesar mungkin untuk memampatkan udara dan menahan tegangan tekanan (pressure pulse) dari siklus ram, memungkinkan aliran air secara tetap melalui pipa pengantar dan kehilangan tenaga karena gesekan diperkecil. Jika ruang udara penuh air, ram akan bergetar keras dan dapat mengakibatkan ruang udara pecah. Jika hal ini terjadi ram harus dihentikan dengan segera. Beberapa ahli menyarankan bahwa volume ruang udara harus sama dengan volume air dalam pipa pengantar. Pada pipa pengantar yang panjang hal ini akan membutuhkan ruang udara yang terlalu besar dan untuk itu sebaiknya dirancang ruang udara dengan ukuran yang kecil.

\section{Katup Udara (Air Valve)}

Udara yang tersimpan dalam ruang udara dihisap perlahan-lahan oleh turbulensi air yang masuk melalui katup pengantar dan hilang ke dalam pipa pengantar. Udara ini harus diganti harus diganti dengan udara baru melalui katup udara. Katup udara harus disesuaikan sehingga mengeluarkan semprotan air yang kecil setiap terjadinya denyutan kompresi. Jika katup udara terbuka terlalu besar, maka ruang udara terisi dengan udara dan ram akan memompa udara. Jika katup kurang terbuka sehingga tidak memungkinkan masuknya udara yang cukup banyak maka ram akan bergetar. Keadaan ini harus diperbaiki dengan memperhatikan besar lubang udara.

\section{Pipa Pengantar (Delivery Pipe)}

Hidraulik ram dapat memompa air pada ketinggian yang cukup tinggi. Dengan menggunakan pipa pengantar yang panjang akan menyebabkan ram harus mengatasi gesekan antara air dengan dinding pipa. Pipa pengantar dapat dibuat dari bahan apapun, termasuk pipa plastik tetapi dengan syarat bahan tersebut dapat menahan tekanan air.

\section{Keragaan (Performance) PATM}

Efisiensi PATM dapat dihitung dengan dua cara, yaitu cara Rankine dan Daubuisson (Addison, 1964). Pada cara Rankine datum yang dipilih adalah permukaan air pada bak pemasukan. Energi masuk adalah energi yang dihasilkan air melalui katup limbah. Sedangkan energi yang keluar energi yang digunakan untuk mengangkat air setinggi (Hd Hs) di atas datum. 


\section{Kelebihan dan Kekurangan PATM}

Kelebihan dari PATM adalah Unik, Hemat, Murah, Hasil Guna Tinggi dan Sederhana, sedangkan Kekurangan dari PATM adalah Bunyi pompa terlalu keras, PATM belum mampu untuk menyediakan Air Baku dalam skala yang luas, Suku Cadang cepat rusak, Pompa jenis ini masih tergolong mahal dan jika debit pada sumber air berkurang, maka pompa air tidak akan bekerja secara kontuinitas dan maksimal.

\section{Cara Operasional PATM}

PATM dapat dioperasikan jika pengerjaan seluruh konstruksi telah selesai. Pintu air atau lubang penguras bendungan harus dalam keadaan tertutup rapat dengan papan berukuran lebar $25 \mathrm{~cm}$ dan panjang $1 \mathrm{~m}$. Apabila bendungan sudah penuh dan permukaan air telah mencapai puncak ketinggian, pengoperasian PATM dapat dilaksanakan.

\section{Ketersediaan Air}

Ketersediaan air dalam pengertian sumber daya air pada dasarnya berasal dari air hujan (atmosferik), air permukaan dan air tanah. Hujan yang jatuh di atas permukaan pada suatu Daerah Aliran Sungai (DAS) atau Wilayah Sungai (WS) sebagian akan menguap kembali sesuai dengan proses iklimnya, sebagian akan mengalir melalui permukaan dan sub permukaan masuk ke dalam saluran, sungai atau danau dan sebagian lagi akan meresap jatuh ke tanah sebagai pengisian kembali (recharge) pada kandungan air tanah yang ada.

\section{Air Permukaan dan Air Tanah}

Air tawar berasal dari dua sumber, yaitu air permukaan (surface water) dan air tanah (ground water). Air permukaan adalah air yang berada di sungai, danau, waduk, rawa dan badan air lain, yang tidak mengalami infiltrasi ke bawah tanah. Sedangkan Air tanah (groundwater) merupakan air yang berada di bawah permukaan tanah. Air tanah ditemukan pada aliran air di bawah permukaan tanah. permeabilitas dari lapisan tanah, dan pengisian kembali air.

\section{Debit Air}

debit dapat diartikan sebagai volume air yang mengalir per satuan waktu melewati suatu penampang melintang palung sungai, pipa, pelimpah, akuifer dan sebagainya. Data debit diperlukan untuk menentukan volume aliran atau perunahan - perubahannya dalam suatu sistem das.

\section{METODE PENELITIAN}

Langkah-langkah untuk meninjau kinerja Pompa Air Tanpa Motor (PATM) untuk suplai air baku masyarakat adalah sebagai berikut :

1) Pengumpulan Data-Data :

a) Peta dan data topografi

b) Denah Lokasi Jaringan PATM

c) Survey Lokasi dan Wawancara Masyarakat Sekitar Lokasi PATM

2) Pengolahan Data meliputi :

a) Menganalisis Ketersediaan Air untuk Menggerakkan PATM

b) Tinjauan Kinerja PATM Dasar dari peninjauan kinerja yaitu untuk menganalisis prinsip, cara kerja dan operasional lapangan PATM 
sehingga penulis dapat memberikan gambaran dari efisiensi teknologi ini kepada masyarakat luas.

c) Kondisi PATM

Secara umum teknologi PATM ini dapat digunakan untuk memenuhi kebutuhan air baku, irigasi, pertanian dan perkebunan, namun disatu sisi juga penulis ingin meninjau kondisi pompa pada saat ini yang telah banyak membantu kebutuhan air baku untuk masyarakat.

\section{HASIL PENELITIAN DAN PEMBAHASAN}

Ketersediaan Air
Saluran Irigasi Alale (Saluran Primer) yang terletak pada Desa Alale, Kec. Suwawa, Kab. Bone Bolango nyatanya hingga saat ini tidak kekurangan air, dikarenakan ada beberapa sungai dan mata air yang dapat menunjang ketersediaan air di Sungai Bone untuk mengalirkan air ke Saluran Primer Alale.

Debit Air dapat dihitung dengan Metode Pengamatan Lapangan. Dengan metode ini debit air yang masuk pada saluran irigasi dapat dinyatakan dengan pasti, dalam hal ini data yang digunakan adalah data debit air pada Saluran Primer Alale yang didapatkan dari instansi terkait. Hasil Pengamatan Lapangan dapat dilihat dengan jelas pada Tabel 1 berikut ini.

Tabel 1. Debit Air

\begin{tabular}{|c|c|c|c|c|c|c|c|c|c|c|c|c|c|c|c|c|c|c|c|c|c|c|c|c|c|c|}
\hline \multirow{3}{*}{0} & \multirow{3}{*}{ WNI } & \multicolumn{24}{|c|}{ BUAN } & \multirow{3}{*}{ PERTHWW } \\
\hline & & \multicolumn{2}{|c|}{$|A|$} & \multicolumn{2}{|c|}{ IFP } & \multicolumn{2}{|c|}{ WHR } & \multicolumn{2}{|c|}{ APR } & \multicolumn{2}{|r|}{ No } & \multicolumn{2}{|r|}{$\| W$} & \multicolumn{2}{|c|}{ UIV } & & & \multicolumn{2}{|c|}{ OUT } & \multicolumn{2}{|c|}{ NOI } & \multicolumn{2}{|c|}{ DES } & \\
\hline & & 15015 & & 15015 & & 15015 & 165 & 15015 & 516500 & sol. & 51650 & & $5 \mid 165 / 1030$ & 15015 & 16501031 & 15015 & 16501031 & & 1650300 & $15 d 151$ & 1665031 & & 1650030 & & 165031 & \\
\hline & 2000 & . & $\cdot$ & . &. & . & & & & & . & . & & . & & & . & $\cdot$ & 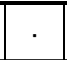 & . & . & . & $\cdot$ & & & \\
\hline & 101. & 331117 & 125,512. & & 48533 & 34485 & 15,021 & 80,155 & 5619 & 5901212 & 56,4 & 78,115 & $5,52,45$ & 15,492 & 47,00 & 35,255 & 3500 & 52,44 & . & 30,47 & & & 48,356 & 55,133 & 20,109 & 4,865 \\
\hline & 2012 & 34,399 & 37513 & 19577 & 555,18 & 6550 & 19,797 & 6,338 & $847,8$. & & 140.1 & & 46,39 & 79,779 & 6, 659 & 35,127 & 26,17 & 191717 & 18558 & 14019 & 34,441 & 51,299 & 59,44 & 84,65 & 74,87 & 43,600 \\
\hline d & 2013 & 45,393 & $34,1,36$ & 37712 & 212,30 & 25,594 & 21,912 & 68,600 & $31,1,4$. & 52,350 & 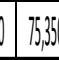 & 35,549 & $4 \quad 20,46$ & 38,09 & 4,1,15 & 38,49 & 393,34 & 44,58 & 3115151 & 15,964 & 14,47 & 30,055 & 34,564 & $71,4,13$ & 55,007 & 39265 \\
\hline 5 & 2014 & 39,25 & 21,50 & 15,515 & 112910 & 17,344 & 58,955 & 52,363 & 3860 & 54,270 & 53480 & 71,463 & 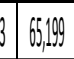 & 60,78 & 56,188 & 4,2,887 & 1232102 & 50394 & 34553 & 24,399 & 17,599 & 32,194 & 58,591 & 53,184 & 56,893 & 46,00 \\
\hline & 2015 & 560551 & 50,287 & 64,48 & 580951 & 339112 & 50,641 & 54,301 & 56,49 & 55,565 & 55282. & 56,61 & 154,213 & 61,367 & 59662 & 586801 & 78035 & 45,338 & 21,34 & 26,18 & 19087 & . & 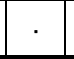 & & 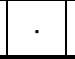 & 5,162 \\
\hline$\pi$ & & 2089,55 & 1810108 & 137,12 & 198,272 & 197,066 & $(33,2,255$ & 1667,148 & 822987 & II, 1,2 & 6321 & $44,1,24$ & 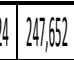 & 255,471 & 20124 & 201,189 & 301373 & $210,2] 3$ & 1056560 & $\mid 110,107$ & 853334 & 113,499 & 200,760 & 263995 & 210,997 & 45,322 \\
\hline
\end{tabular}

Berdasarkan data diatas dapat disimpulkan bahwa Debit Air pada Saluran Irigasi Alale tidak terjadi penurunan yang signifikan dari tahun ke tahun, sehingga memang pantas Pemerintah Provinsi Gorontalo, melalui Bidang Sumber Daya Air Dinas PU Provinsi Gorontalo telah membangun teknologi baru untuk kebutuhan air baku masyarakat di masa yang akan datang, yaitu JIS (Jaringan Irigasi) PATM. Sehingga pada daerah - daerah yang masih kekurangan air dapat memanfaatkan teknologi ini sebagai kebutuhan sehari - hari.

Dalam hasil penelitian ini terdapat perbandingan jumlah debit air yang yang diperlukan lahan pertanian dan untuk pompa 
itu sendiri. Dengan menggunakan jumlah persentasi untuk kebutuhan lahan pertanian sekitar 62\% dan kebutuhan pompa 38\% (angka kebutuhan nyata di lapangan), angka ini didapatkan dari hasil survey instansi terkait pada waktu perencanaan pembuatan PATM, maka diperoleh hasil analisa yang dijabarkan pada Tabel 2. berikut :

Tabel 2. Perbandingan Jumlah Debit Air

\begin{tabular}{|c|c|c|c|}
\hline TAHUN & $\begin{array}{c}\text { DEBT RERATA PER TAHUN } \\
\text { (I/det) }\end{array}$ & $\begin{array}{c}\text { UnTUK LAHAN PERTANIAN } \\
\text { (//det/ha) }\end{array}$ & UNTUK PATM (//det) \\
\hline 2011 & 44,865 & 27,816 & 17,049 \\
\hline 2012 & 43,760 & 27,131 & 16,629 \\
\hline 2013 & 39,265 & 24,344 & 14,921 \\
\hline 2014 & 46,609 & 28,898 & 17,711 \\
\hline 2015 & 52,162 & 32,340 & 19,822 \\
\hline Jumlah & 226,661 & 140,530 & 86,131 \\
\hline Rerata & 45,332 & 28,106 & 17,226 \\
\hline
\end{tabular}

Debit air yang masuk di saluran juga dapat mempengaruhi efisiensi PATM yang sudah terpasang, sehingga pada pembuatannya telah dilakukan uji debit air yang masuk pada 1 unit PATM. Sehingga didapatkan debit air yang masuk pada 1 unit PATM ini yang bisa dilihat pada Tabel 3 berikut :

\section{Tabel 3. Debit Air Masuk Di Saluran}

\begin{tabular}{|c|c|c|c|}
\hline \multirow{2}{*}{ ULANGAN } & \multirow{2}{*}{ DEBIT MASUK (1/det) } & TINGGI 3,84 M & TINGGI5,45 M \\
\cline { 3 - 4 } & & Debit (1/det) & Debit (1/det) \\
\hline 1 & 24,59 & 3,55 & 3,00 \\
\hline 2 & 24,11 & 3,57 & 3,16 \\
\hline 3 & 24,41 & 3,56 & 3,17 \\
\hline 4 & 24,48 & 3,60 & 3,10 \\
\hline 5 & 23,76 & 3,55 & 3,08 \\
\hline Jumlah & 121,35 & 17,33 & 15,51 \\
\hline Rerata & 24,27 & 3,57 & 3,10 \\
\hline
\end{tabular}

Tinjauan Kinerja PATM

Prinsip Kerja Pompa Hidram
Prinsip kerja hidram adalah pemanfaatan gravitasi dimana akan menciptakan energi dari hantaman air yang menabrak faksi air lainnya untuk mendorong ke tempat yang lebih tinggi. Untuk mendapatkan energi potensial dari hantaman air diperlukan syarat utama yaitu harus ada terjunan air yang dialirkan melalui pipa dengan beda tinggi elevasi dengan pompa hidram minimal 1 meter. Syarat utama kedua adalah sumber air harus kontinyu dengan debit minimal 7 liter per menit. Skema prinsip kerja pompa hidram ini dapat dilihat pada gambar 1 berikut ini.

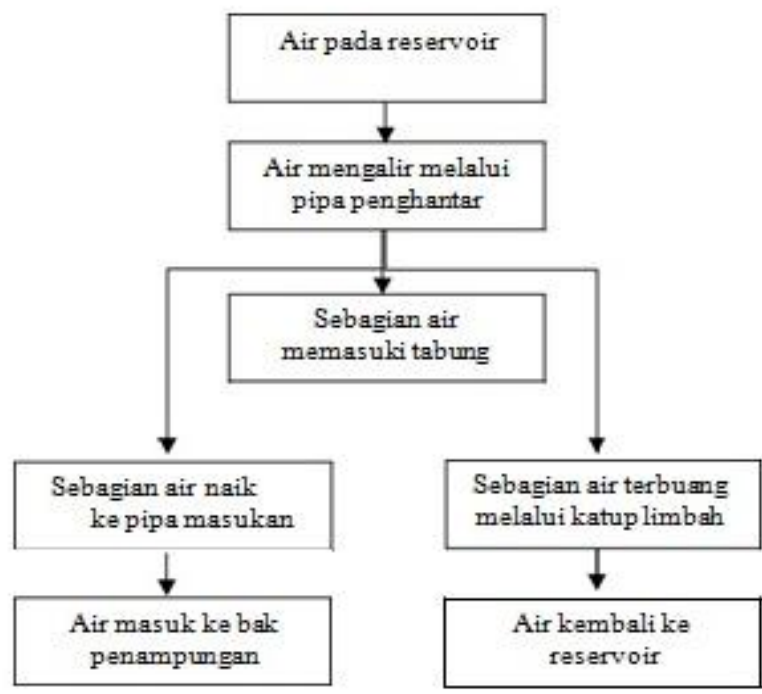

Gambar 1. Skema Prinsip Kerja Pompa Hidram

Bagian kunci dari hidram adalah dua buah klep, yaitu : klep pembuangan dan klep penghisap. Air masuk dari terjunan melalui pipa A, klep pembuangan terbuka sedangkan klep penghisap tertutup. Air yang masuk memenuhi rumah pompa mendorong ke atas klep pembuangan hingga menutup.

Dengan tertutupnya klep pembuangan mengakibatkan seluruh dorongan air menekan dan membuka klep penghisap dan air masuk 
memenuhi ruang dalam tabung kompresi di atas klep penghisap.

Pada volume tertentu pengisian air dalam tabung kompresi optimal, massa air dan udara dalam tabung kompresi akan menekan klep penghisap untuk menutup kembali, pada saat yang bersamaan sebagian air keluar melalui pipa B. Dengan tertutupnya kedua klep, maka aliran air dalam rumah pompa berbalik berlawanan dengan aliran air masuk, diikuti dengan turunnya klep pembuangan karena arah tekanan air tidak lagi ke klep pembuangan tetapi berbalik ke arah pipa input A.

Di sinilah hantaman ram palu air (water hammer) itu terjadi, dimana air dengan tenaga gravitasi dari terjunan menghantam arus balik tadi, 2/3 debit keluar lubang pembuangan, sementara yang $1 / 3$ debit mendorong klep penghisap masuk ke dalam tabung pompa sekaligus mendorong air yang ada dalam tabung pompa untuk keluar melaui pipa output B. Energi hantaman yang berulang-ulang mengalirkan air ke tempat yang lebih tinggi.

Secara sederhana prinsip kerja PATM ialah apabila aliran air dalam pipa tertutup tiba - tiba berhenti, maka terjadi proses perubahan energi kinetik air menjadi tekanan dinamik yang disebut sebagai fenomena palu air (water hammer), sehingga terjadi tekanan tinggi dalam pipa. Dengan mengusahakan katup limbah dan katup hantar dalam tabung pompa bekerja dan menutup dan membuka secara bergantian, maka tekanan dinamik diteruskan sehingga energi yang terjadi dalam pipa masuk (inlet) akan memaksa air naik ke pipa pengeluaran (outlet) dan diteruskan ke pipa hantar.

\section{Sistem Kerja PATM}

Ada tiga bagian utama jaringan PATM, yakni :

1. Sumber air dapat berupa danau, aliran sungai, kolam, atau bendungan kecil dengan debit paling sedikit $20 \mathrm{lt} / \mathrm{det} / 1$ PATM.

2. Satuan pompa dipasang minimum 2 meter dibawah sumber air, dengan menggunakan pipa (diameter 6") dengan panjang antara 18 dan 24 meter dari sumber air.

3. Jaringan pipa pengeluaran dan pipa penghantar sampai ke bak penampung. Berikut ini adalah bagian utama dalam PATM yang akan digambarkan pada gambar 2.

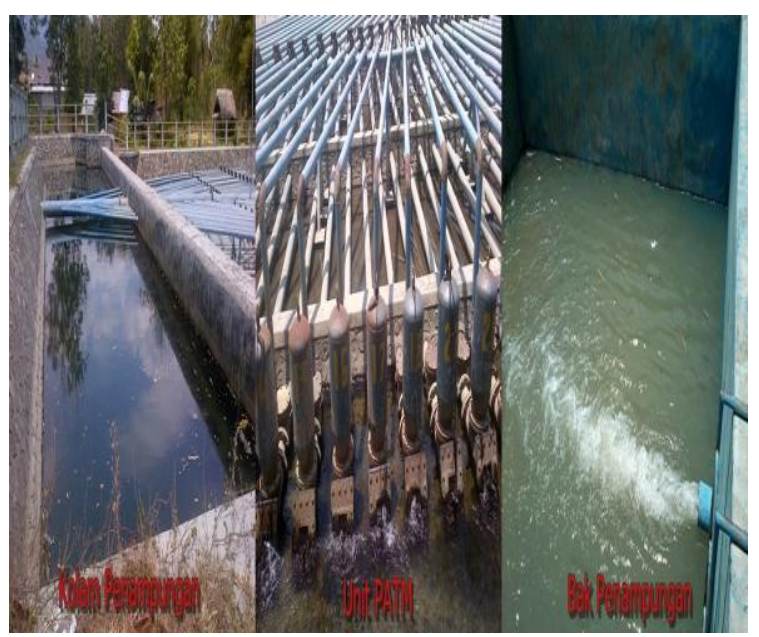

Gambar 2. Jaringan Pipa Pengeluaran Dan Pipa Penghantar

\section{Teknis Pemasangan PATM}

Pekerjaan utama konstruksi PATM adalah :

1. Pembuatan bendung, dapat dikerjakan dengan cara 
a. Non permanen : dibuat dengan tumpukan karung pasir, jika lebar sungai kurang dari lima meter

b. Semi Permanen : dibuat dengan kawat bronjong, jika debit air besar dan lebar sungai antara 15 dan 25 meter.

c. Permanen :dibuat dengan pasangan batu dan beton bertulang, pondasi bendungan harus sampai pada tanah keras atau cadas.

d. Disalah satu sisi bendung dibuat bangunan pelimpah untuk melimpahkan air pada waktu banjir.

2. Pekerjaan dudukan PATM

PATM dapat dipasang lebih dari satu, berjejer sesuai dengan debit air yang diperlukan. Setiap satuan PATM diletakkan pada dudukan, yakni pasangan batu atau cor, agar stabil dan tidak berubah posisi saat dioperasikan. Dudukan harus kuat karena tekanan aliran air melalui pipa pemasukkan ke dalam tabung pompa dapat menimbulkan getaran yang sangat kuat. Pompa dipasang dengan menggunakan angker

3. Pengurasan Bendung

Apabila bendung sudah penuh dengan pasir atau batu - batuan maka dilakukan pengurasan dengan membuka pintu penguras yang terbuat dari buis beton.

4. Pemasangan pipa pemasukan (inlet)

Pipa inlet terbuat dari pipa galvanis ukuran 6". Setiap sambungan pipa harus diperkuat dengan plenes, baud mur, dan paking karet supaya tidak terjadi kebocoran air. Pipa inlet harus disangga oleh pipa penyangga atau pasangan batu yang disesuaikan dengan kecuraman sungai.

5. Pemasangan Pipa Outlet

Pipa pengeluaran atau pipa penghantar merupakan pipa penyalur air dari tabung pompa ke daerah yang dikehendaki. Besaran pipa pengeluaran dari tabung pompa beragam, yakni 2", 3", 4", 5", dan 6" tergantung dari banyakanya debit air yang diperlukan. Pipa pengeluaran dapat dipasang secara paralel dengan beberapa PATM sesuai dengan jarak dan ketinggian daerah tujuan. Pipa pipa paralel atau pipa - pipa gabungan ini harus disangga dengtan dudukan atau pipa penyanga dan ditransblok sebagai penguat pipa penyangga.

\section{Kondisi PATM}

Pada tahun 2006 sampai dengan pada tahun 2015 sekarang, PATM Desa Alale sudah beberapa kali maintenance (perbaikan), mulai dari penggantian suku cadang seperti paking karet, baut mur, dan as katup dikarenakan pompa yang bekerja selama 24 jam tanpa henti. Penggantian suku cadang ini dilakukan berkala karena efisiensi pompa sangatlah penting untuk kebutuhan suplai air baku untuk masyarakat setempat yang mengandalkan PATM.

Di tahun 2015 sekarang unit PATM ini telah mengalami kerusakan dengan unit yang rusak ada 9 pompa. Kerusakan ini diakibatkan oleh beberapa faktor seperti kondisi pompa yang bekerja terendam air sehingga beberapa 
komponen mengalami keausan, kurangnya teknisi handal untuk menangani kerusakan di lapangan, biaya penggantian suku cadang yang mahal dan suku cadangnya harus di pesan terlebih dahulu di pabrik pembuatannya sehingga faktor waktu pemesanan dan pengiriman kadang menjadi kendala untuk perbaikan, serta minimnya dana yang tersedia untuk dianggarkan pada unit pompa ini.Kerusakan ini sangat berpengaruh terhadap pengisian bak penampung yang berada di Desa Tingkohubu, berdekatan dengan Polres Bone Bolango, karena selama ini PATM menyuplai air untuk kebutuhan pertanian, danau perintis, dan air baku yang selalu diandalkan masyarakat setempat, sehingga beberapa penanganan awal terhadap kerusakan pompa telah dilakukan oleh Pemerintah Provinsi Gorontalo melalui Dinas Pekerjaan Umum Bidang Sumber Daya Air.

Berikut adalah tabel perbandingan kondisi pompa normal dan rusak yang dapat dilihat pada tabel 4.

Tabel 4. Perbandingan Kondisi Pompa Normal Dan Rusak

\begin{tabular}{|c|c|c|c|c|}
\hline \multirow{2}{*}{ ULANGAN } & \multicolumn{2}{|c|}{ NORMAL (40 POMPA) } & \multicolumn{2}{c|}{ RUSAK (9 POMPA) } \\
\cline { 2 - 5 } & Debit Masuk|/det) & Debit Keluar (//det) & Debit Masuk (//det) & Debit Keluar (//det) \\
\hline 1 & 983,6 & 142,40 & 762,29 & 110,36 \\
\hline 2 & 964,4 & 142,40 & 747,41 & 110,36 \\
\hline 3 & 976,4 & 142,40 & 756,71 & 110,36 \\
\hline 4 & 979,2 & 142,40 & 758,88 & 110,36 \\
\hline 5 & 950,4 & 142,40 & 736,56 & 110,36 \\
\hline Jumlah & 4854,00 & 712,00 & 3761,85 & 551,80 \\
\hline Rerata & 970,8 & 142,40 & 752,37 & 110,36 \\
\hline
\end{tabular}

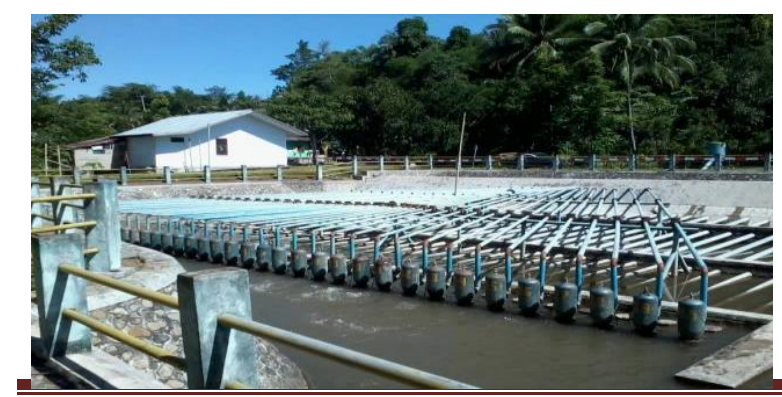

Gambar 3. Kondisi PATM Di Lokasi Penelitian

\section{KESIMPULAN}

1. Berdasarkan hasil penelitian di lapangan dan data yang dikumpulkan, debit air yang ada tidak mempengaruhi efisiensi PATM itu sendiri, debit yang diperoleh dalam beberapa tahun terakhir dengan jumlah rerata yang ada adalah 45,332 liter/detik dan untuk kebutuhan debit air pada PATM didapatkan hasil rerata 17,226/detik.

2. PATM adalah teknologi pompa terbaru dengan menggunakan pemanfaatan gravitasi dimana akan menciptakan energi dari hantaman air yang menabrak faksi air lainnya untuk mendorong ke tempat yang lebih tinggi.

3. Kondisi pompa saat ini telah mengalami kerusakan sebanyak 9 unit pompa, hal ini sangat berpengaruh terhadap kebutuhan air baku yang sering dimanfaatkan oleh masyarakat sekitarnya untuk kebutuhan lahan pertanian dan perkebunan.

\section{SARAN}

1. PATM sangat diperlukan oleh masyarakat karena disaat sekarang teknologi dari PATM ini sendiri tanpa menggunakan Listrik ataupun Motor namun bekerja dengan mengandalkan tekanan air, sehingga dapat menekan biaya produksidi masyarakat.

2. Pemanfaatan PATM ini sangat dibutuhkan masyarakat untuk lahan dan pertanian dan air baku, sehingga perlunya efisiensi dari pemanfaatan pompa ini sendiri untuk kebutuhan air di masa yang akan datang. 


\section{DAFTAR PUSTAKA}

Addison, 1964, "Mechanics of Fluids" Mc.Graw Hill Higher Education, United Kingdom

Anonim, 2014, "Pompa Hidram" Direktorat Pengelolaan Air, Departemen Pertanian

Bouwer, 1978, "Groundwater Hydrology" Mc.Graw-Hill Higher Education, United Kingdom

Hefnie, E, 2003, "Telaah Kualitas Air" Kanisius, Yogyakarta

Kalsim, D, 2002, "Teknik Irigasi dan Drainase", Departemen Teknik Pertanian Institut Pertanian Bogor.

Kementerian PU Direktorat Jenderal Sumber Daya Air, Republik Indonesia Standar Perencanaan Irigasi 1986, "Kriteria Perencanaan Saluran KP - 03”, Kementerian PU Direktorat Jenderal Sumber Daya Air, Republik Indonesia

Soemarto, 1987, "Hidrologi Teknik" PT. Pradnya Paramita, Surabaya

Sri Harto, 2000, "Analisis Hidrologi" Gramedia Pustaka Utama, Jakarta

Standar Perencanaan Irigasi 1986, “Kriteria Perencanaan Bagian Jaringan Irigasi KP - OI",

Suripin, 2002, "Pelestarian Sumber Daya Tanah dan Air" Andi Yogyakarta

Triadmodjo, 2010, "Hidrologi Terapan Jilid II' Beta Offset, Yogyakarta

Watt, 1974 " A Manual on the Hydraulic RAM for Pumping Water” ITDG Publishing, United Kingdom

Widarto, S, 1997, "Membuat Pompa Hidram", Kanisius, Yogyakarta. hal, 14 